\title{
QUANTITATIVE HISTOCHEMICAL EFFECTS OF WHISKER DAMAGE ON SINGLE IDENTIFIED CORTICAL BARRELS IN THE ADULT MOUSE $^{1}$
}

\author{
W. DALTON DIETRICH, ${ }^{*}, 2$ DIANNE DURHAM,‡ OLIVER H. LOWRY,* AND THOMAS A. WOOLSEY
}

Departments of *Pharmacology and $\ddagger$ Anatomy and Neurobiology and $\ddagger$ McDonnell Center for Studies of IIigher Brain Function, Washington University School of Medicine, St. Louis, Missouri 63110

\begin{abstract}
The whiskers on the face of mice project through several synapses to anatomically distinct cortical structures called barrels. In this study, the activities of six energy-related enzymes in isolated barrels in layer IV in the somatosensory cortex of adult mice were determined using quantitative histochemical techniques. Data from control barrels and from barrels for which the corresponding whiskers had been damaged were obtained. The analyses were made on freeze-dried cryostat sections. Individual barrels were identified in unstained sections and subsequently, portions of them were dissected out and weighed on a quartz fiber balance. Micromethods for histochemistry, including the use of oil wells and enzymatic cycling amplification, were used. Because only small samples were needed ( 25 to $40 \mathrm{ng}$ ), the levels of several enzymes in the same barrel or the distribution of an enzyme within parts of a single barrel could be determined. The following enzyme levels (given in moles per $\mathrm{kg}$ dry weight per $\mathrm{hr} \pm \mathrm{SE}$ ) were observed in controls: citrate synthase, $5.3 \pm 0.15$; malate dehydrogenase, $20.8 \pm 0.90$; hexokinase, $5.2 \pm 0.25$; lactate dehydrogenase, $10.6 \pm 0.20$; glycogen phosphorylase, $0.374 \pm 0.031$; and glucose-6-phosphate dehydrogenase, $0.638 \pm 0.012$. In single barrels, the mitochondrial enzyme, citrate synthase, had a higher activity within the barrel hollowwhich is richer in mitochondria- $(7.2 \pm 0.12)$ as compared to the barrel side-which is poorer in mitochondria- $(4.4 \pm 0.22)$. The activities of these six enzymes were determined in particular barrels following cauterization of the related groups of whiskers in adult mice. For example, 60 days after whisker damage, activities expressed as a percentage of control were: citrate synthase, $69 \%$; malate dehydrogenase, $61 \%$; hexokinase, $79 \%$; lactate dehydrogenase, $92 \%$; glycogen phosphorylase, $132 \%$; and glucose-6-phosphate dehydrogenase, $112 \%$. These significant enzymatic changes occurred in the adult mouse brain in spite of the fact that the injury to peripheral tactile organs was three synapses away. Moreover, no anatomical changes in the barrels have been reported after similar damage to the periphery. We interpret the changes in enzyme levels as a manifestation of adaptive "plasticity" in the sense that the metabolic machinery of a neural system is matched to its metabolic need, which, in this case, is reduced as a consequence of reduced neuronal activity.
\end{abstract}

The development of the nervous system can be altered following various types of experimental manipulations. For example, when a sensory system is deprived of input chronically, functional as well as structural changes are observed (Hubel et al., 1977; Woolsey, 1978; Parks, 1979). However, most studies report that the morphological and functional changes can be induced only during a specific "critical" or "sensitive" period in the development of the organism (Jacobson, 1978). Usually after this moment,

\footnotetext{
1 This work was supported by United States Public Health Service Grants NS 07057, NS 15070, NS 10244, NS 08862, and NS 07129 and American Cancer Society Grant BC4W. We wish to thank Bob Freund for photography and Mary Murphy for typing.

2 To whom correspondence should be addressed at Department of Pharmacology, Washington University School of Medicine, 660 South Euclid Avenue, St. Louis, MO 63110.
}

no major structural changes can be produced (e.g., Woolsey and Wann, 1976; LeVay et al., 1980). Recently, with the use of histochemical staining procedures, regional changes in the levels of enzymes involved in energy metabolism have been demonstrated following chronic sensory deprivation in the adult brain (Wong-Riley et al., 1978). In their study of the mouse somatosensory cortex, Wong-Riley and Welt (1980) demonstrated a decrease in the level of the mitochondrial enzyme, cytochrome oxidase, within barrels for which the corresponding whiskers had been cauterized 80 days previously. ${ }^{3}$ Anatomically,

\footnotetext{
Mice and other rodents have five rows of large whiskers on the face. Each whisker is associated with a single tactile organ or sinus hair which receives a substantial, well segregated afferent innervation from the maxillary division of the trigeminal nerve. The rows of whiskers or mystacial vibrissae are labeled $\mathrm{A}$ to $\mathrm{F}$ from dorsal to ventral on the
} 
no gross changes in barrel morphology are seen in similar experiments (Woolsey and Wann, 1976).

The objective of the present study was to characterize more fully the histochemistry of individual barrels within the posteromedial $b$ arrel subfield (PMBSF) through the use of quantitative microtechniques. The levels of enzymes within normal barrels were measured. The activities of various enzymes within barrels for which the corresponding whiskers had been damaged were followed at selected times after whisker damage. These activities were compared directly to the activities within barrels in the same section associated with intact vibrissae. This paper reports base line levels of a number of enzymes related to energy metabolism in normal barrels and quantitates the consequences of chronic sensory deafferentation occurring three synapses away within the adult nervous system.

\section{Materials and Methods}

\section{Preparation of tissue}

Twenty-two adult Swiss Webster mice of both sexes were used in this study. In 18 mice, the whiskers in rows $B$ and $D$ of both sides of the face were plucked and their follicles were cauterized under Nembutal anesthesia. Experimental animals were allowed to survive for $15,45,60$, 90 , and 115 days. At this time, facial pads were examined grossly to verify the damage to the whiskers within the treated rows. In some cases, the pattern and the extent of peripheral damage were determined from hematoxylin and eosin-stained paraffin sections of facial skin. In one additional experimental animal, the infraorbital branch of the trigeminal nerve was sectioned surgically on the right side. This animal was sacrificed 60 days later. Mice were decapitated and the heads were frozen directly in liquid nitrogen chilled to its freezing point $\left(-210^{\circ} \mathrm{C}\right)$. The brains were dissected out in a $-20^{\circ} \mathrm{C}$ cold room and the cerebral hemispheres were mounted in a cryostat for tangential sectioning through the PMBSF (Woolsey and Van der Loos, 1970). The sections $(20 \mu \mathrm{m})$ were dried overnight at $-35^{\circ} \mathrm{C}$ and stored under vacuum at $-35^{\circ} \mathrm{C}$ until the analyses were carried out. Details of the preparation of tissues and sections are described by Lowry and Passonneau (1972).

Under a dissecting microscope and with appropriate transmitted illumination, specific barrels could be identified routinely within unstained freeze-dried sections. From these sections, single barrels were isolated and each barrel was subdivided further so that the levels of several enzymes could be determined in the same barrel (Fig. 1) or so that the regional distribution of a single enzyme

face. These project to the cortex through three synapses-in the ipsilateral trigeminal nuclei, in the contralateral ventrobasal thalamus, and in the somatosensory ( $\mathrm{SmI}$ ) cortex. The cell bodies in layer IV of this cortex are arranged as cytoarchitectonic units called barrels which extend throughout layer IV and which, when viewed in sections parallel to the pial surface, have a pattern which is "isomorphic" to the whiskers on the face. Thus, in the posteromedial barrel subfield (PMBSF), there are five rows of barrels labeled $\mathrm{A}$ to $\mathrm{E}$, from caudal to rostral, which correspond to and receive inputs in a one-to-one fashion from the similarly named five rows of large whiskers on the contralateral face.
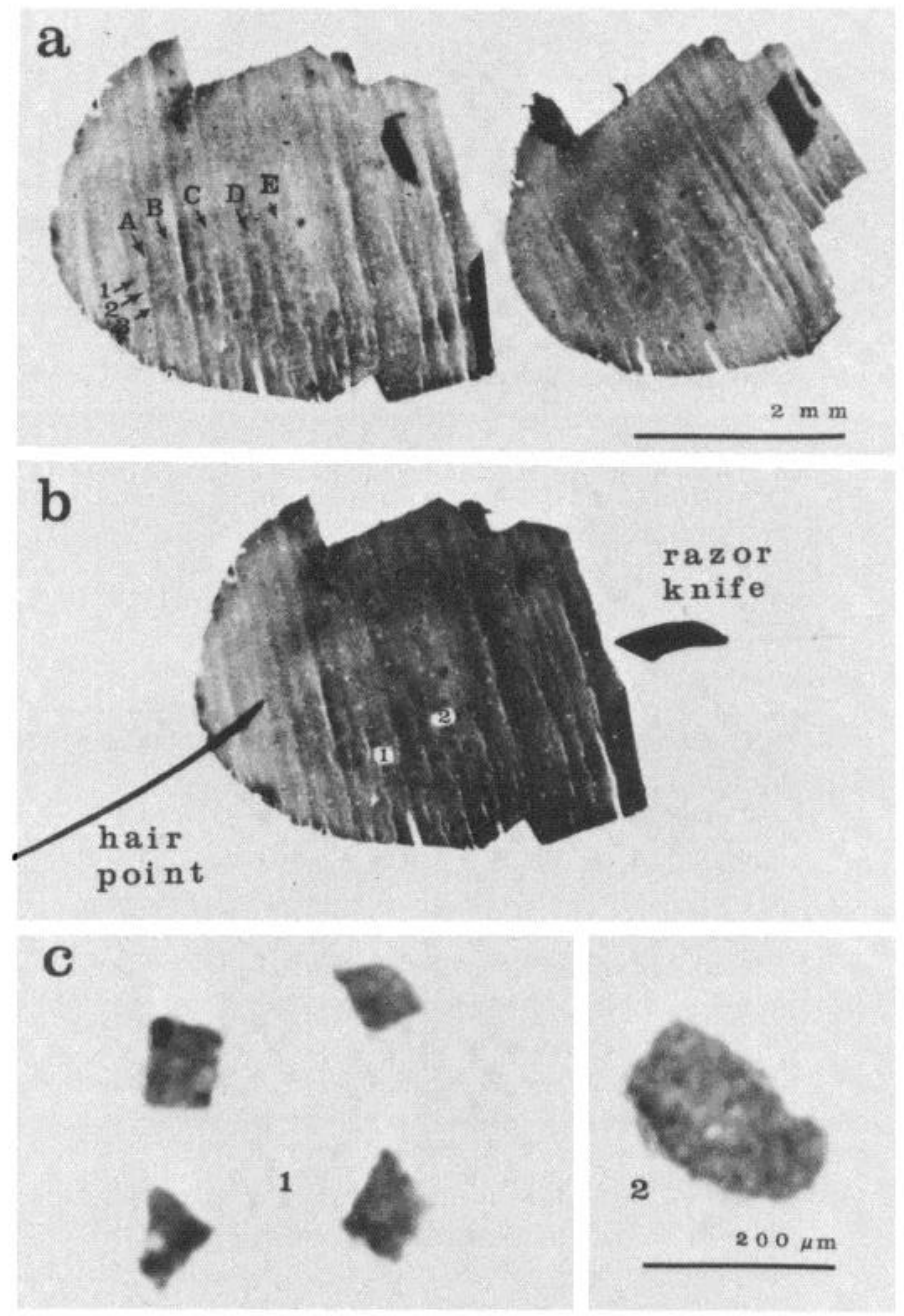

Figure 1. The method for dissecting individual identified barrels from a $20-\mu \mathrm{m}$ freeze-dried tangential section is shown. $a$, In two unstained nonadjacent sections, rows of barrels ( $A$ to $E$ ) can be seen as are the barrels in each row (i.e., $l$ to 3 ). $b$, Special dissecting instruments, hair point and razor knife, are shown for scale. Two barrels $\left(1, \mathrm{C}_{4}\right.$ and $\left.2, \mathrm{E}_{4}\right)$ have been dissected out of the section. $c$, These two dissected barrels are shown. Barrel 1 has been quartered and could be used for four separate determinations of the levels of a single enzyme or for the assay of the levels of up to four different enzymes.

within a particular barrel could be studied (Fig. 2). Immediately following dissection, samples were weighed on a quartz fiber fishpole balance (Lowry, 1953) and analyzed.

\section{Analytic methods}

General assay procedure. In all cases, the first analytical step was carried out under oil in an "oil well rack" because of the small sample size (Matschinsky et al., 1968; Lowry and Passonneau, 1972). Samples were loaded directly into specific reagents, and after incubation for 1 $\mathrm{hr}$ at $20^{\circ} \mathrm{C}, \mathrm{NaOH}$ or $\mathrm{HCl}$ was added to stop the reaction. All of the methods are based directly or indirectly on pyridine nucleotide enzyme reactions. The enzyme, malate dehydrogenase, had sufficient activity so that the oxidation of the nucleotide could be measured directly. 
In the remaining assays, the reduced or oxidized nucleotide product was amplified by enzymatic cycling. During cycling, the pyridine nucleotide was alternately oxidized by one enzyme and then reduced back again by another in a cyclic fashion. After a sufficient number of cycles, one of the products which accumulates was measured. The result was a large gain in sensitivity. For $\mathrm{NAD}^{+}$, the cycling reagent described by Kato and Lowry (1973) and for NADP, that from Chi et al. (1978) were used. Following the cycling step, the reaction mixtures were heated at $100^{\circ} \mathrm{C}$ for $3 \mathrm{~min}$ and then cooled to room temperature in a water bath. Indicator reagent was added and the fluorescence was measured after the reaction was complete. Appropriate standards and blanks were used to calculate the level of enzyme activity.

An individual assay system. Several procedures were modified for the present study from Lowry et al. (1978) (citrate synthase and glycogen phosphorylase), Hintz et al. (1980) (malate dehydrogenase), and Kato and Lowry (1973) (lactate dehydrogenase, glucose-6-phosphate dehydrogenase, and hexokinase). Since these methods have been described in detail previously, it is not necessary to discuss each here. However, to illustrate the principles underlying these analytical procedures, the assay for the determination of citrate synthase will be described. The steps in the assay are as follows: the subsequent heating of the oil rack at $95^{\circ} \mathrm{C}$ for $30 \mathrm{~min}$. After cooling, $10 \mu \mathrm{l}$ of citrate reagent containing $100 \mathrm{~mm}$ Tris- $\mathrm{HCl}, \mathrm{pH}$ 7.0, $0.03 \mathrm{~mm} \mathrm{NADH}, 0.04 \mathrm{~mm} \mathrm{ZnCl}_{2}, 0.01 \%$ bovine serum albumin, $1 \mu \mathrm{g} / \mathrm{ml}$ of beef heart malate dehydrogenase (EC 1.1.1.37), and $5 \mu \mathrm{g} / \mathrm{ml}$ of Aerobacter aerogenes citrate lyase was incubated for $20 \mathrm{~min}$ at room temperature, and the excess NADH was destroyed with $2 \mu \mathrm{l}$ of $0.5 \mathrm{~N} \mathrm{HCl}$. After at least $10 \mathrm{~min}$ at room temperature, a $1-\mu \mathrm{l}$ aliquot from the oil well was added to $50 \mu \mathrm{l}$ of $\mathrm{NAD}^{+}$cycling reagent in small test tubes and cycled approximately 1000 times. After $60 \mathrm{~min}$, the test tubes were heated for $5 \mathrm{~min}$ at $95^{\circ} \mathrm{C}$ to stop the cycling. One milliliter of indicator reagent was added to the tubes, yielding a fluorescent product that was measured in a fluorometer. For each specimen and enzyme measured, up to 15 independent assays were done to calculate a mean and standard error.

\section{Results}

Control studies. The results obtained from three control animals are presented in Table I. Of the enzymes assayed, the activity of malate dehydrogenase was the greatest $(20.8 \mathrm{~mol} / \mathrm{kg}$ dry weight $/ \mathrm{hr})$ and glycogen phosphorylase was the least $(0.374 \mathrm{~mol} / \mathrm{kg}$ dry weight $/ \mathrm{hr})$, a 55 -fold difference. Each barrel extends throughout the thickness of layer IV, a distance of about $120 \mu \mathrm{m}$, and

(1) Oxalacetate and acetyl-CoA $\rightarrow$ citrate $+\mathrm{CoA}$

citrate

(2) Citrate $\rightarrow$ acetate + oxalacetate lyase

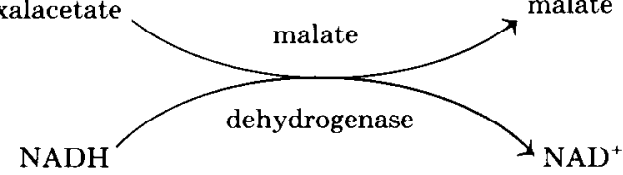

(3) Cycling step:

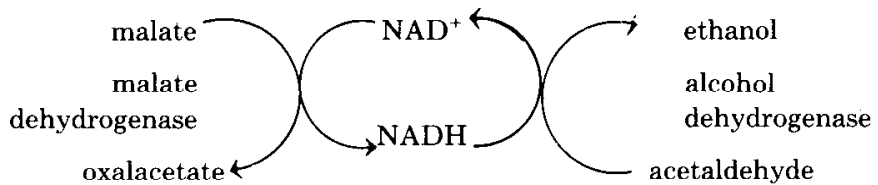

(4) Indicator step:

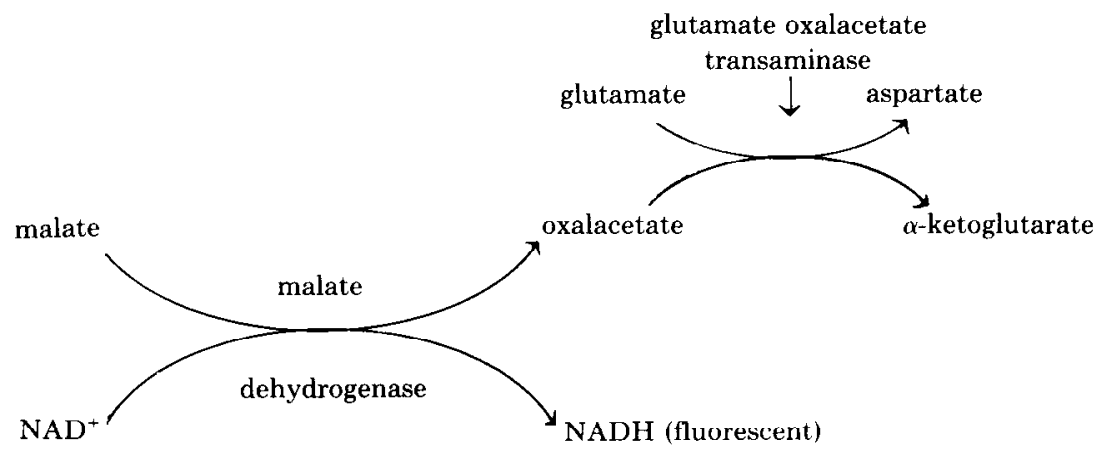

The specific reagent for this assay contained $50 \mathrm{~mm}$ Tris-HCl buffer, $\mathrm{pH} 7.8,0.4 \mathrm{~mm}$ acetylcoenzyme A (acetyl-CoA), $0.5 \mathrm{~mm}$ oxalacetate, and $0.25 \%$ citrate-free bovine serum albumin. Citrate standards were provided in this first reagent at concentrations of 0.05 and $0.10 \mathrm{~mm}$ in the same volume used for the samples. In step 1, after acetyl-CoA reacted with oxalacetate, the oxalacetate excess was destroyed by the addition of $0.05 \mathrm{~N} \mathrm{NaOH}$ and therefore can be recognized in five to seven adjacent serial sections. Possible variations in enzyme activity as a function of depth in layer IV were examined directly using the same barrel (i.e., $\mathrm{C}_{1}, \mathrm{C}_{2}$, or $\mathrm{C}_{3}$ ) from four serial sections. For example, the activities of the enzyme citrate synthase in such a series were $5.32,5.51,5.44$, and 5.66 $\mathrm{mol} / \mathrm{kg}$ dry weight $/ \mathrm{hr}$, indicating that the activity of this enzyme was relatively constant throughout the depth of 


\section{TABLE I}

Enzyme activity in normal barrels

Averages $( \pm \mathrm{SE})$ are shown for four to five barrels from each of three control animals. For each enzyme, its principal intracellular location is indicated.

Enzyme
Citrate synthase (mitochondria)
Malate dehydrogenase (mitochon-
dria, cytosol)

Activity

mol/kg dry wt./hr

$5.15 \pm 0.16$

$5.39 \pm 0.32$

$5.32 \pm 0.11$

$20.4 \pm 0.72$

$20.8 \pm 1.10$

$21.4 \pm 0.81$

Hexokinase (largely mitochondria)

Lactate dehydrogenase (cytosol)

$5.15 \pm 0.31$

$5.30 \pm 0.20$

$5.26 \pm 0.28$

$10.6 \pm 0.23$

$10.2 \pm 0.15$

$11.2 \pm 0.16$

Glycogen phosphorylase (cytosol)

$0.354 \pm 0.021$

$0.369 \pm 0.040$

$0.396 \pm 0.035$

Glucose-6-phosphate dehydrogenase (microsomes)

$0.615 \pm 0.016$

$0.665 \pm 0.013$

$0.633 \pm 0.018$

layer IV. Similar studies were done for all of the enzymes analyzed and in no case was a significant difference in enzyme activity observed as a function of depth. Barrels from different rows in the same brain had similar enzymatic activities as did barrels from different animals. In another control study, we examined the regional distribution of a mitochondrial enzyme within a barrel, since it is known from a number of anatomical studies that mitochondria are concentrated heavily in the barrel center or hollow (White, 1976; Labedsky and Lierse, 1968). Figure 2 shows that the activity of the mitochondrial enzyme citrate synthase, as expected, was higher in the hollow than in the side.

Effects of whisker damage. In the experimental animals, changes in the activities of all enzymes were demonstrated in barrels corresponding to the damaged row $B$ and $D$ whiskers. Substantial decreases in the activities of citrate synthase and malate dehydrogenase (Fig. 3, $A$ and $B$ ) over the 115-day period were observed. Barrels dissected from rows $A, C$, and $E$ of these experimental animals had enzymatic activities that were comparable to those in control animals, represented by the horizontal dotted lines in Figure 3. Hexokinase, the first enzyme in glycolysis, also showed a large decrease in activity over the 115-day period with no change in control barrels (Fig. $3 C)$. Lactate dehydrogenase showed, at most, a small decrease in activity during the period of study (Fig. 3D). In complete contrast, total glycogen phosphorylase increased in activity (Fig. 3E). Additionally, the "control barrels" had a modest increase in activity when compared to barrels within normal animals. Finally, unlike any of the other enzymes studied, glucose-6-phosphate dehydrogenase showed a biphasic response (Fig. $3 F$ ).

Between days 15 and 45, this enzyme decreased in activity; by 60 days, it had returned to about control levels; and by 115 days, it was 25\% above control. For this enzyme, values from "control" barrels within experimental animals were similar to those from control animals.

In the one animal in which the infraorbital branch of the trigeminal nerve was cut, changes in enzymes at 60 days were indistinguishable from those observed following whisker damage (Fig. 3). As there is reason to believe that the cauterization of the vibrissal follicle damages the sensory nerves to them, which, in young animals, can lead to degeneration in the primary afferents (Waite and Cragg, 1979), this result constitutes an important control.

\section{Discussion}

This study demonstrates that reproducible values for enzymatic activities can be obtained from individual barrels and that pronounced changes in enzyme levels are observed in appropriate barrels following whisker damage in adult mice. Our quantitative results confirm the presence of the enzymatic changes after whisker damage demonstrated by Wong-Riley and Welt (1980) and show that a number of enzymes are affected, both mitochondrial and non-mitochondrial. ${ }^{4}$

The activities of each of the six enzymes measured were nearly identical whether the samples were taken from the same barrel or from barrels in different animals. The finding of no significant difference in enzyme activities as a function of depth in layer IV allowed for the direct comparison of a large number of samples from several sections through the barrels in this lamina. The unequal distribution of activity of citrate synthase throughout a single barrel is expected from the anatomically demonstrated distribution of mitochondria within a barrel (White, 1976; Labedsky and Lierse, 1968; WongRiley and Welt, 1980). These data serve as anatomical controls for the quantitatively demonstrated regional differences of citrate synthase within a single barrel found in this study.

The "barrels" in the mouse SmI cortex are known to receive inputs across three synapses from the large whiskers on the contralateral face in a one-to-one fashion. Following whisker removal, time-dependent changes in the levels of all six enzymes studied were observed in corresponding barrels when compared either to barrels from control animals or to adjacent "normal" barrels in the same section. The finding of decreased activity of the enzymes hexokinase, citrate synthase, and malate dehydrogenase is indicative of a decreased capacity of these areas of the brain to oxidize glucose. Interestingly, lactate dehydrogenase, an enzyme that, under anaerobic conditions, reduces pyruvate to lactic acid, did not show a large decrease in activity. The biphasic response of glucose-6-phosphate dehydrogenase, which catalyzes the initial reaction of the hexose monophosphate pathway or shunt, is unique among the enzymes measured in this

\footnotetext{
${ }^{4}$ Unfortunately, at the moment, there is no good micro-assay for cytochrome oxidase from which quantitative data could be obtained for direct comparison to the levels of this enzyme demonstrated histologically.
} 


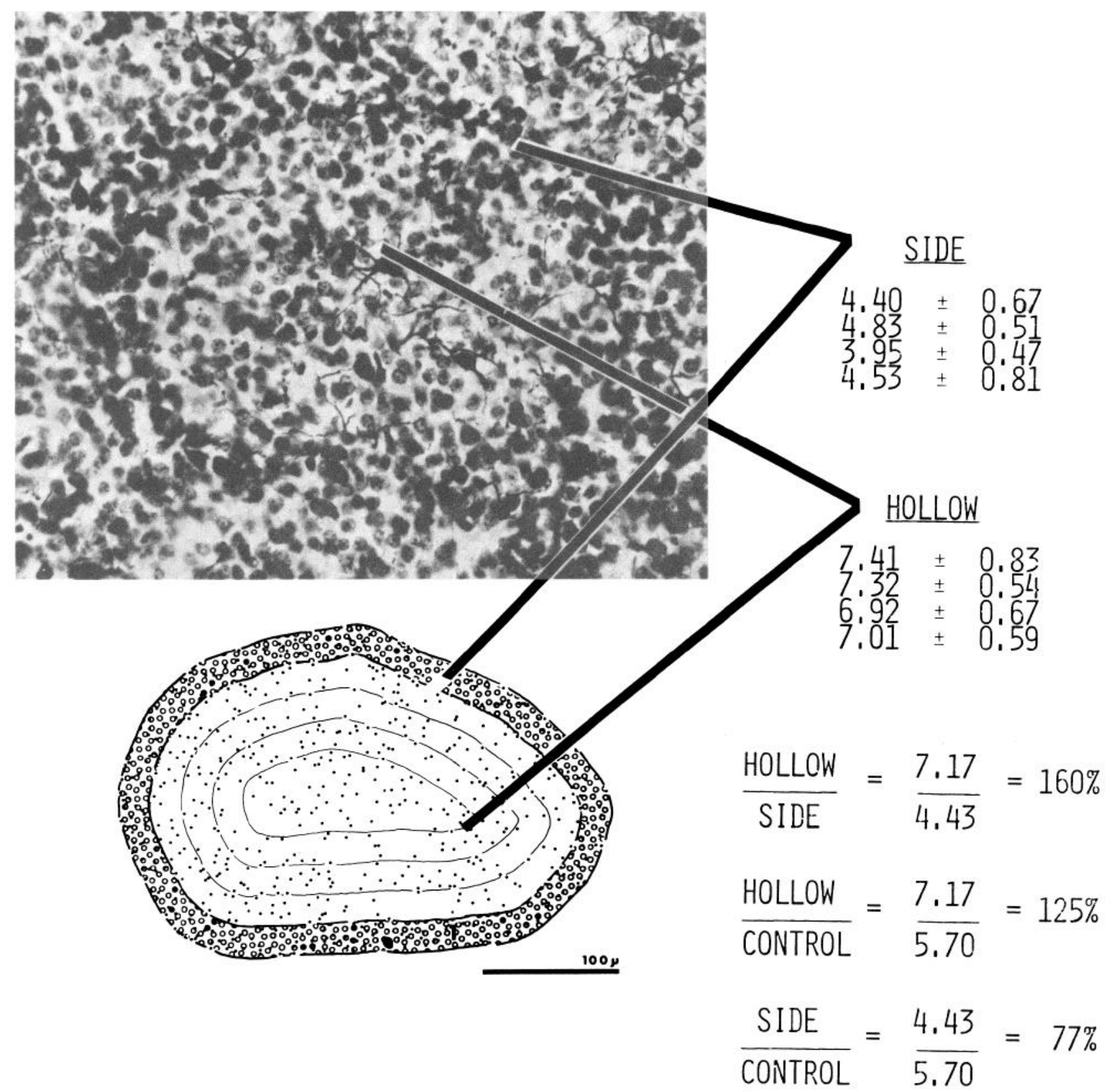

Figure 2. Comparison of regional differences in neuronal packing in a barrel and the level of the mitochondrial enzyme citrate synthase recorded as moles $\mathrm{kg}^{-1}$ (dry weight) $\mathrm{hr}^{-1} \pm \mathrm{SE}$. Above left, A photomicrograph of a tangential Golgi-Nissl-stained section of the mouse SmI cortex shows a single barrel. From this picture and the schematic drawing below it, it can be seen that a barrel consists of a ring of greater cell density (the side; open circles) surrounding an area of cells and neuropil (the hollow). In the schematic representation, the dots in the hollow show the positions of neuronal somata. Other anatomical methods demonstrate more mitochondria in the hollow than in the side. The activity of the mitochondrial enzyme, citrate synthase, is more concentrated in the barrel hollow of the four individual barrels analyzed in this manner as expected from anatomical studies.

study. McDougal et al. (1961) demonstrated higher activities of this enzyme in white matter than in grey matter, but it is not known whether the enzyme is present mainly in axons or glia. Such information would be helpful in localizing enzymatic changes to one of the two broad classes of central nervous system cells. Glycogen phosphorylase rose monotonically over the period of study, indicating an increased capacity to utilize stored energy.

This is one of the first quantitative histochemical studies of a central nervous system sensory system fol- lowing experimental manipulation. Similar changes in some enzymes have been demonstrated in other excitable tissues subsequent to experimental manipulation. For example, in skeletal muscle, investigators have reported a decrease in mitochondrial enzymes following denervation and, most interestingly, after long term limb immobilization (Karpati and Engel, 1968; Max, 1973; Rifenberick et al., 1973). These procedures also resulted in muscle atrophy (Max, 1973).

One possible interpretation of the changes which we 

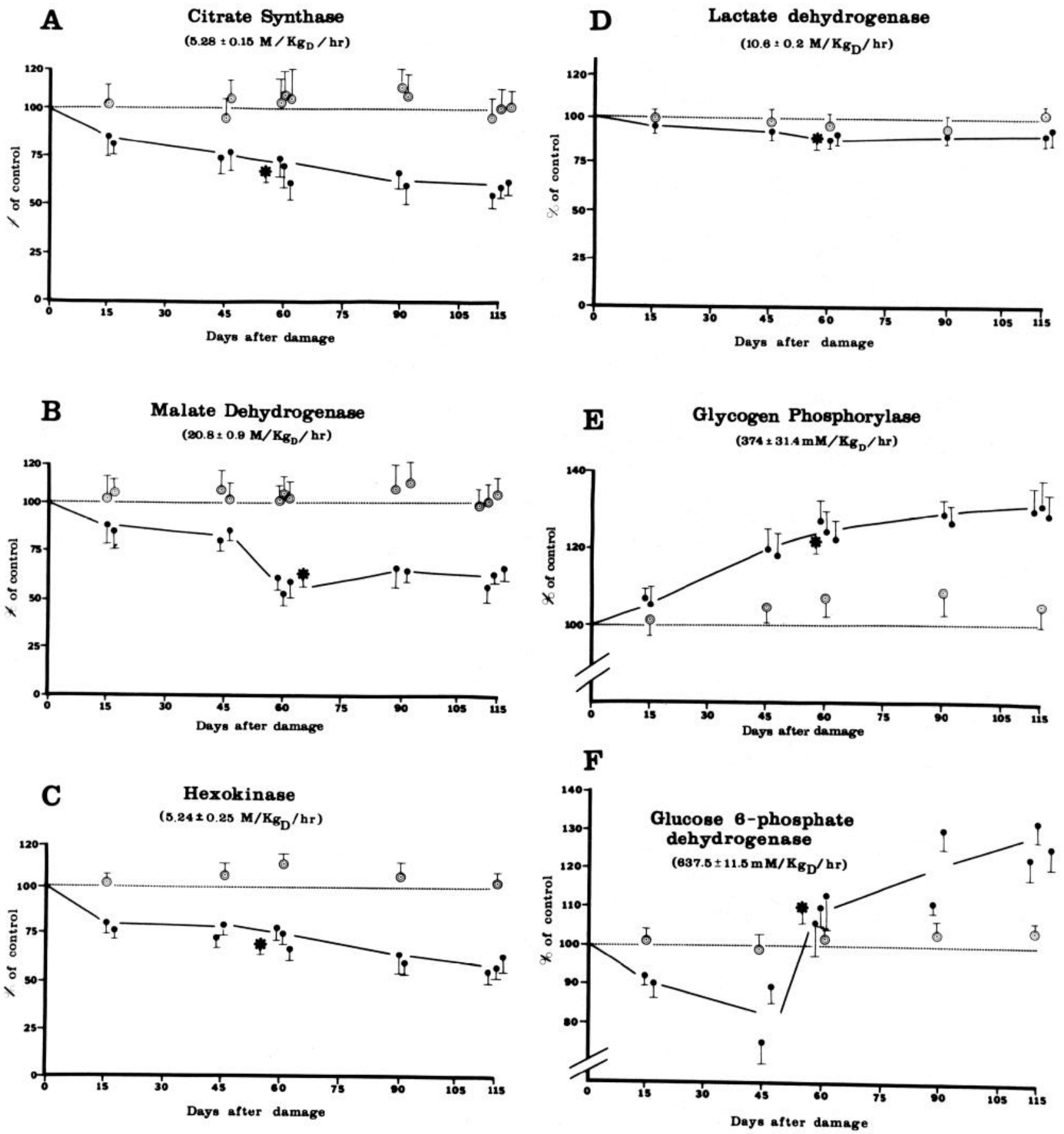

Figure 3. Time course of changes in the activities of the six enzymes studied. For each panel $(A$ to $F)$, the enzyme studied is identified, and its control level of activity $\pm \mathrm{SE}$ (obtained from three control animals) is indicated and plotted as $100 \%$ of the control activity by the dashed lines. Activities are recorded as moles kg ${ }^{-1}$ (dry weight) $\mathrm{hr}^{-1}\left(\mathrm{M} / \mathrm{Kg}_{\mathrm{D}} / \mathrm{hr}\right.$ ). Mean values obtained from experimental barrels (rows $B$ and $D, 0$ ) are recorded; those which came from control barrels (rows $A, C$, and $E$, () ) from the same section are in register. The bars show SE. Values obtained from barrels in the animal in which the right infraorbital nerve was sectioned 60 days prior to sacrifice are shown also (*). These are comparable to whisker-damaged animals. Note that, for each enzyme studied, the experimental manipulation produced changes in enzyme activities.

report is that they correspond to degenerative events. However, a transneuronal degeneration across three synapses in adults is unlikely (Cowan, 1970), and recently, Wong-Riley (1980) presented evidence which argues against a degenerative effect. Specifically, her electron micrographs of barrels from similarly prepared animals did not show a change in the morphology or the extent of supporting cell profiles. The interpretation which we favor for our results is that the metabolic changes are a reflection of long standing inactivity within this neural system, an idea that has some support from functional studies of similarly prepared animals (Simons et al., 1980) as opposed to demonstrated short term changes in glucose utilization (Durham and Woolsey, 1978; Durham et 
al., 1981). Perhaps the most interesting issues relate to how neuronal activity or lack of it, as expressed by action potentials, can influence metabolic processes in the relevant cells. Presumably, the metabolic changes which our results describe are a manifestation of adaptive "plasticity" in the nervous system in the sense that the metabolic machinery of a neuron is matched to its metabolic needs. To study this phenomenon further, we are presently looking at the consequences of sensory deprivation as opposed to the effects of denervation reported here. It will be of interest to see if there are similar metabolic changes and, if so, whether they can be reversed by reversing the deprivation.

This study demonstrates the potential for the characterization of sensory systems through the use of quantitative histochemical procedures, especially following experimental manipulation. Distinctive regions of the brain, such as the barrels, can be identified in freezedried tissue samples and various analytic procedures can be carried out. Once these methods of identifying and obtaining tissues have been developed, then the concentration of other interesting substances, such as metabolites and suspected neurotransmitters, can be measured. We are exploring this possibility currently.

\section{References}

Chi, M. M., C. V. Lowry, and O. H. Lowry (1978) An improved enzymatic cycle for nicotinamide-adenine dinucleotide phosphate. Anal. Biochem. 89: 119-129.

Cowan, W. M. (1970) Anterograde and retrograde transneuronal degeneration in the central and peripheral nervous system. In Contemporary Research Methods in Neuroanatomy, W. J. H. Nauta and S. O. E. Ebbesson, eds., pp. 217-251, Springer, New York.

Durham, D., and T. A. Woolsey (1978) Acute whisker removal reduces neuronal activity in barrels of mouse $\mathrm{SmI}$ cortex. J. Comp. Neurol. 178: 629-644.

Durham, D., T. A. Woolsey, and L. W. Kruger (1981) Cellular localization of $2-\left[{ }^{3} \mathrm{H}\right]$ deoxy-D-glucose from paraffin-embedded brains. J. Neurosci. 1: 519-526.

Hintz, C. S., C. V. Lowry, K. K. Kaiser, D. McKee, and O. H. Lowry (1980) Enzyme levels in individual rat muscle fibers. Am. J. Physiol. 239: 58-65.

Hubel, D. H., T. N. Wiesel, and S. LeVay (1977) Plasticity of ocular dominance columns in monkey striate cortex. Philos. Trans. R. Soc. Lond. (Biol.) 278: 377-409.

Jacobson, M. (1978) Developmental Neurobiology, Plenum Press, New York.

Karpati, G., and W. K. Engel (1968) Correlative histochemical study of skeletal muscle after suprasegmental denervation, peripheral nerve section, and skeletal fixation. Neurology ( $N$. Y.) 18: 681-692.

Kato, T., and O. H. Lowry (1973) Enzymes of energy-converting systems in individual mammalian nerve cell bodies. J. Neurochem. 20: 151-163.
Labedsky, L., and W. Lierse (1968) Die entwicklung der succinodehydrogenaseaktivität im Gehirn der maus während der postnatalzeit. Histochemie 12: 130-151.

LeVay, S., T. N. Wiesel, and D. H. Hubel (1980) The development of ocular dominance columns in normal and visually deprived monkeys. J. Comp. Neurol. 191: 1-51.

Lowry, C. V., J. S. Kimmey, S. Felder, M. M. -Y. Chi, K. K. Kaiser, P. N. Passonneau, K. A. Kirk, and O. H. Lowry (1978) Enzyme patterns in single human muscle fibers. J. Biol. Chem. 253: 8269-8277.

Lowry, O. H. (1953) The quantitative histochemistry of the brain. J. Histochem. Cytochem. 1: 420-428.

Lowry, O. H., and J. V. Passonneau (1972) A Flexible System of Enzymatic Analysis, Academic Press, New York.

Matschinsky, F. M., J. V. Passonneau, and O. H. Lowry (1968) Quantitative histochemical analysis of glycolytic intermediates and cofactors with an oilwell technique. J. Histochem. Cytochem. 16: 29-39.

Max, S. R. (1973) Muscular atrophy: Activation of mitochondrial ATPase. Biochem. Biophys. Res. Commun. 52: 12781284.

McDougal, D. B., D. W. Schulz, J. V. Passonneau, J. R. Clark, M. A. Reynolds, and O. H. Lowry (1961) Quantitative studies of white matter. J. Gen. Physiol. 44: 487-498.

Parks, T. N. (1979) Afferent influences on the development of the brainstem auditory nuclei of the chicken: Otocyst ablation. J. Comp. Neurol. 183: 665-678.

Rifenberick, D. H., J. G. Gamble, and S. R. Max (1973) Response of mitochondrial enzymes to decreased muscular activity. Am. J. Physiol. 225: 1295-1299.

Simons, D. J., D. Durham, and T. A. Woolsey (1980) Functional organization of mouse and rat barrel cortex following whisker damage on different postnatal days. Soc. Neurosci. Abstr. 6: 638.

Waite, P. M. E., and B. G. Cragg (1979) The effect of destroying the whisker follicles in mice on the sensory nerve, the thalamocortical radiation and cortical barrel development. Proc. R. Soc. Lond. (Biol.) 204: 41-55.

White, E. L. (1976) Ultrastructure and synaptic contacts in barrels of mouse SI cortex. Brain Res. 105: 229-251.

Wong-Riley, M. T. T. (1980) Cortical barrel fields of adult mice as analyzed with cytochrome oxidase cytochemistry. Soc. Neurosci. Abstr. 6: 655.

Wong-Riley, M. T. T., and C. Welt (1980) Histochemical changes in cytochrome oxidase of cortical barrels after vibrissal removal in neonatal and adult mice. Proc. Natl. Acad. Sci. U. S. A. 77: 2333-2337.

Wong-Riley, M. T. T., M. M. Merzenich, and P. A. Leake (1978) Changes in endogenous enzymatic reactivity to DAB induced by neuronal inactivity. Brain Res. 141: 185-192.

Woolsey, T. A. (1978) Some anatomical bases of cortical somatotopic organization. Brain Behav. Evol. 15: 325-371.

Woolsey, T. A., and H. Van der Loos (1970) The structural organization of layer IV in the somatosensory region (SI) of mouse cerebral cortex. Brain Res. 17: 205-242.

Woolsey, T. A., and J. R. Wann (1976) Areal changes in mouse cortical barrels following vibrissal damage at different postnatal ages. J. Comp. Neurol. 170: 53-66. 